\title{
Correction to: Isolation and characterization of Xanthomonas euvesicatoria pv. euvesicatoria causing bacterial spot in Physalis pubescens in Northeast China
}

\author{
Shuang Song ${ }^{1} \cdot$ Yao Zhang ${ }^{1}$ (D) $\cdot$ Huan Liu $^{2} \cdot$ Chun-Qing Pan ${ }^{1} \cdot$ Ming-Xiu Yang ${ }^{1} \cdot$ Jing-Feng Ding ${ }^{1} \cdot$ Jun-Hua Zhang ${ }^{1}$ \\ Published online: 17 May 2019 \\ (C) Società Italiana di Patologia Vegetale (S.I.Pa.V.) 2019
}

Correction to: Journal of Plant Pathology (2019) 101:361-366

https://doi.org/10.1007/s42161-018-0193-9

This correction stands to correct erroneous funding shown in the original article. The authors would like all to know that the correct funding is the University Nursing Program for Young Scholars with Creative Talents in Heilongjiang Province (No. uNPYSCT-2018157), and not the former: uNPYSCT-2018157, 17QC05 and C2017032. The original article has been corrected.

Publisher's note Springer Nature remains neutral with regard to jurisdictional claims in published maps and institutional affiliations.

The online version of the original article can be found at https://doi.org/ 10.1007/s42161-018-0193-9

Jun-Hua Zhang

podozjh@163.com

1 Department of Plant Protection, College of Agriculture, Northeast Agricultural University, Harbin 150030, China

2 State Key Laboratory of Crop Stress Biology for Arid Areas, College of Plant Protection, Northwest A\&F University, Yangling 712100, China 